Harbhej Singh MD FFARCSI, Jay Yang MD PhD, Katina Thornton MD, Adolph H. Giesecke MD

\title{
Intrathecal fentanyl prolongs sensory bupivacaine spinal block
}

The purpose of investigation was to study the effect of intrathecal fentanyl on the onset and duration of hyperbaric bupivacaine-induced spinal block in adult male patients. Fortythree patients undergoing lower extremity or genitourinary surgery were enrolled to receive either $13.5 \mathrm{mg}$ hyperbaric bupivacaine $0.75 \%+0.5 \mathrm{ml} \mathrm{CSF}$ it, (Group I) or $13.5 \mathrm{mg} h \mathrm{y}$ perbaric bupivacaine $0.75 \%+25 \mu \mathrm{g}$ fentanyl it, (Group II) according to a randomized assessor-blind protocol. The onset and duration of sensory block were assessed by pinching the skin with forceps in the midclavicular line bilaterally every two minutes for first twenty minutes and then every five to ten minutes. Similarly, the onset and duration of motor block were assessed and graded at the same time intervals using the criteria described by Bromage. The time required for two sensory segment regression and sensory regression to $L_{l}$ dermatome was $74 \pm 18$ and $110 \pm 33 \mathrm{~min}$ vs $93 \pm 22$ and $141 \pm 37 \mathrm{~min}$ in Groups I and II, respectively $(P<0.05)$. Intrathecal fentanyl did not enhance the onset of sensory or motor block, or prolong the duration of bupivacaine-induced motor spinal block. Fewer patients demanded pain relief in the fentanyl-treated group than in the control group in the early postoperative period $(19 \%$ vs 59\%; $P<0.05$ ). Episodes of hypotension were more frequent in the fentanyl-treated group than in the control group $43 \%$ vs $14 \% ; P<0.05$ ). We conclude that fentaml, $25 \mu \mathrm{g}$ it, prolonged the duration of bupivacaine-induced sensory block (sensory regression to $L_{1}$ dermatone) by $28 \%$ and reduced the analgesic requirement in the early pastoperative period following bupivacaine spinal block.

Cette étude a pour objectif d'examiner l'effet du fentamyl sousarachnoïdien sur le début et la durée de la rachianesthésie

\section{Key words}

ANAESTHETIC TECHNIQUES: spinal;

ANAESTHETICS, LOCAL: bupivacaine;

ANALGESICS: fentanyl, intrathecal.

From the Department of Anesthesiology and Pain

Management, University of Texas Southwestern Medical

Center, 5323 Harry Hines Blvd, Dallas, Texas 75235-9068.

Address correspondence to: Dr. Harbhej Singh.

Accepted for publication 30th June, 1995. hyperbare à la bupivacaine chez des patients adultes de sexe masculin. Quarante-trois patients opérés sur une extrémité inférieure ou sur l'appareil génito-urinaire sont répartis pour recevoir au hasard en rachianesthésie soit $13,5 \mathrm{mg}$ de bupivacaüne hyperbare à $0,75 \%$ avec $0,5 \mathrm{ml}$ de LCR (groupe I), soit 13,5 $\mathrm{mg}$ de bupivacaïne hyperbare à $0,75 \%$ avec $25 \mu \mathrm{g}$ de fentanyl (groupe II). Le début et la durée du bloc sont évalués en coinçant la peau avec une pince sur la ligne médioclaviculaire bilatéralement à toutes les deux minutes pour les 20 premières minutes et à toutes les cing à dix minutes par la suite. En même temps, le début et la durée du bloc moteur sont évalués et classé aux mêmes intervalles selon les critères de Bromage. Le temps requis pour la regression de deux segments sensoriels et la régression sensorielle jusqu'au dermatome de $L_{1}$ est de $74 \pm 18$ et $110 \pm 33$ vs $93 \pm 22$ et $141 \pm 37$ min dans les groupes $I$ et II respectivement $(P<0,05)$. Le fentanyl sousarachnoïdien n'accélère pas le début des blocs sensoriel et moteur ni ne prolonge la durée du bloc moteur produit par la bupivacaüne. Moins de patients ont demandé un analgésique dans le groupe fentanyl que dans le groupe contrôle à la période postopératoire immédiate $(19 \%$ vs $59 \%, P<0,05)$. Les épisodes dhypotension sont plus fréquents dans le groupe traité au fentanyl que dans le groupe contrôle (43\% vs $14 \%, P<0,05$ ). Les auteurs concluent que le fentanyl $25 \mu \mathrm{g}$ sous-arachoüdien prolonge la durée du bloc senstif induit par la bupivacaïne (mesurée par la régression au dermatome de $L_{l}$ ) par $28 \%$ et diminue les besoins en analgésie dans le période postopératoire immédiate après une rachianesthésie.

Neuraxial administration of opioids in conjunction with local anaesthetics improves the quality of intraoperative analgesia and prolongs the duration of postoperative analgesia. ${ }^{1,2}$ Animal studies have also demonstrated antinociceptive synergism between intrathecal opioids and local anaesthetics during visceral and somatic nociception. ${ }^{3-7}$

Fentanyl (a lipophilic opioid) has a rapid onset and a shorter duration of action following intrathecal administration but its duration of action may be dosedependent. ${ }^{8,9}$ Hunt et al. reported that the addition of fentanyl $\geq 6.25 \mu \mathrm{g}$ to hyperbaric bupivacaine reduced the intraoperative opioid requirement in patients undergoing 
Caesarean delivery under spinal block. ${ }^{2}$ Belzarena further demonstrated that low-dose fentanyl, $0.25 \mu \mathrm{g} \cdot \mathrm{kg}^{-1} i$, with bupivacaine $0.5 \%$ provided excellent surgical anaesthesia with few side effects. An increased dose of fentanyl, $0.5-0.75 \mu \mathrm{g} \cdot \mathrm{kg}^{-1}$ it, was associated with increased incidence of adverse effects in patients undergoing Caesarean delivery. ${ }^{10}$

Datta et al. demonstrated faster onset of conduction blockade (increased sensitivity) in bupivacaine pre-treated nerve fibres in pregnant than in non-pregnant rabbits. ${ }^{11}$ Given the suggested increased sensitivity to conduction blockade in parturients ${ }^{12}$ and the paucity of comparable data in other population groups, this study was designed to evaluate the effects of intrathecal fentanyl $25 \mu \mathrm{g}(0.3$ $\mu \mathrm{g} \cdot \mathrm{kg}^{-1}$ ) on the onset and duration of hyperbaric bupivacaine-induced sensory and motor spinal block, and the early postoperative analgesic requirements in adult male patients undergoing lower extremity or genitourinary surgery.

\section{Methods}

Following institutional Human Investigation Committee approval, $\mathbf{4 3}$ adult men undergoing elective lower extremity or genitourinary surgery under spinal block consented to participate in this study. Patients were randomly assigned to receive either $1.8 \mathrm{ml}(13.5 \mathrm{mg})$ hyperbaric bupivacaine $0.75 \%$ it $+0.5 \mathrm{ml}$ cerebrospinal fluid (CSF) it (Group I) or $1.8 \mathrm{ml}(13.5 \mathrm{mg}$ ) hyperbaric bupivacaine $0.75 \%+0.5 \mathrm{ml}(25 \mu \mathrm{g})$ fentanyl it (Group II).

After placement of routine non-invasive monitors, intravenous access was established and patients were preloaded with 700-800 ml lactated Ringer's solution. Intravenous infusion was maintained at $4-8 \mathrm{ml} \cdot \mathrm{kg}^{-1} \cdot \mathrm{hr}^{-1}$ during the intraoperative period. Midazolam, $1-4 \mathrm{mg} i v$, was administered to provide anxiolysis and sedation depending upon the preoperative status of the patient. Spinal block was performed with 25-gauge spinal needle at the $\mathrm{L}_{3-4}$ interspace in the lateral decubitus position and bupivacaine, $13.5 \mathrm{mg} i t$, with or without fentanyl $25 \mu \mathrm{g}$ $i t$, was injected according to the random-assignment. The total volume of the subarachnoid injectate was $2.3 \mathrm{ml}$ in both the treatment groups. Patients were immediately returned to the supine position after completion of the block procedure. Mean arterial pressure (MAP) was monitored every two to five minutes in the operating room and every ten to fifteen minutes in the postanaesthesia care unit (PACU). Arterial haemoglobin oxygen saturation $\left(\mathrm{SaO}_{2}\right)$ and ECG leads II and $\mathrm{V}_{5}$, were monitored continuously in the operating room and PACU. The onset and duration of sensory block were assessed by the same investigator blinded to the treatment groups, by pinching the skin with forceps in the midclavicular line bilaterally every two minutes for first $\mathbf{2 0}$ $\min$ and then every five to ten minutes. The time from intrathecal injection to the highest sensory level, regression of sensory level by two segments from the highest sensory level, and sensory regression to the $L_{1}$ dermatome were recorded. The highest level was recorded for unequal height of the sensory block on two sides. The onset and duration of motor block was assessed and graded at the same time intervals using the following criteria described by Bromage. ${ }^{13}$

$\mathbf{0}=$ no impairment of movement of legs and feet;

1 = barely able to flex knees; no impairment of movement of feet;

$2=$ unable to flex knees and barely able to move feet;

$3=$ unable to move feet or knees.

Episodes of perioperative hypotension (MAP $<70$ $\mathrm{mmHg}$ ), bradycardia (HR $<50 \mathrm{bpm}$ ), and desaturation $\left(\mathrm{SaO}_{2}<90 \%\right)$ were also recorded. Hypotensive episodes were treated with boluses of fluid and increments of ephedrine, $5 \mathrm{mg} \dot{i}$, and bradycardia was treated with atropine, $0.2-0.4 \mathrm{mg} \dot{\mathrm{i}}$. In addition, the number of patients experiencing nausea, itching, or shivering, or requesting pain relief during the early postoperative period (within four hours following intrathecal injection) were recorded. Patients were discharged from PACU either upon completion of the study period (four hours following intrathecal injection), or upon complete recovery of the sensory and motor function, whichever the longer of these two durations.

Data were analyzed using unpaired $t$ test, Mann Whitney U rank sum test, and Fisher's exact test, with $P$ $<0.05$ considered statistically significant. Data are presented as mean values $\pm S D$, median (range) values, and numbers (percent).

\section{Results}

The two treatment groups were comparable with respect to ASA physical status, age, weight, height, and the surgical procedures. Most, $64 \%$, of the patients received midazolam, 1-4 mg $i v$, in the control group compared with $62 \%$ in the fentanyl-treated group (Table I).

The highest sensory levels achieved were $T_{8}\left(T_{5-10}\right)$ and $T_{7}\left(T_{6-8}\right)$ in Groups I (control) and II (fentanyl), respectively. The time intervals (durations) for sensory level to regress by two segments from the highest sensory level, and sensory regression to $\mathrm{L}_{1}$ dermatome were prolonged in the fentanyl-treated patients $(26 \%$ and $28 \%$, respectively; $P<0.05$ ) (Table II). Durations of Grade I, II, and III motor blocks were not prolonged in the fentanyltreated group (Table III). The onset of bupivacaineinduced spinal block was not enhanced in the fentanyltreated patients (Tables II and III).

There were no differences in the number of patients experiencing episodes of bradycardia, desaturation, shiv- 
TABLE I Demographic characteristics of the two treatment groups

\begin{tabular}{lcc}
\hline & Control & Fentanyl \\
\hline Number of patients $(n)$ & 22 & 21 \\
Age $(\mathrm{yr})$ & $62 \pm 15$ & $65 \pm 11$ \\
Weight $(\mathrm{kg})$ & $81 \pm 17$ & $82 \pm 13$ \\
Height $(\mathrm{cm})$ & $176 \pm 6$ & $174 \pm 6$ \\
Preoperative sedation $[\mathrm{n}(\%)]$ & $14(64 \%)$ & $13(62 \%)$ \\
\hline
\end{tabular}

Values are either numbers $(n)$ or mean \pm SD or numbers (percent) $(n(\%))$.

No statistically significant differences.

TABLE II Characteristics of sensory block

\begin{tabular}{|c|c|c|}
\hline & Control & Fentanyl \\
\hline $\begin{array}{l}\text { Highest sensory level ( } \mathrm{T}) \text { [median } \\
\text { (range)] }\end{array}$ & $T_{8}\left(T_{5-10}\right)$ & $T_{7}\left(T_{6-8}\right)$ \\
\hline $\begin{array}{l}\text { Time from injection to highest sensory } \\
\text { level (min) }\end{array}$ & $7.1 \pm 2.5$ & $7.5 \pm 3.2$ \\
\hline $\begin{array}{l}\text { Time for two segment regression from } \\
\text { the highest sensory level (min) }\end{array}$ & $74 \pm 18$ & $93 \pm 22 *$ \\
\hline $\begin{array}{l}\text { Time for sensory regression to } L_{1} \text { from } \\
\text { highest sensory level (min) }\end{array}$ & $110 \pm 33$ & $141 \pm 37^{*}$ \\
\hline
\end{tabular}

Values are either median (range) or mean \pm S.D.

${ }^{*} P<0.05$, considered significant (unpaired $t$ test).

ering, itching or nausea between the two treatment groups. Episodes of hypotension were more frequent in the fentanyl-treated group than in the control group (43\% vs $14 \% ; P<0.05$ ). Fewer patients requested analgesic medication in the early postoperative period in the fentanyl-treated group than in the control group (21\% vs $59 \% ; P<0.05$ ) (Table IV).

\section{Discussion}

Results of our study demonstrate that the fentanyl, 25 $\mu \mathrm{g} i$, prolonged the duration of bupivacaine-induced sensory blockade (sensory regression to $\mathrm{L}_{1}$ dermatome) by $28 \%$. This suggests a potential synergism between fentanyl and bupivacaine as reported in an animal study by Wang et $a l^{7}$ However, there was no prolongation of the duration of motor block. ${ }^{2,3}$ Also, intrathecal fentanyl did not enhance the onset of bupivacaine-induced spinal block, as previously reported by Hunt et al. for parturients undergoing Caesarean delivery. ${ }^{2}$

Opioids and local anaesthetics exert their antinociceptive effect in the spinal cord by different mechanisms. The $\mu$-agonist, fentanyl, exerts its action by opening $\mathrm{K}^{+}$ channels and reducing $\mathrm{Ca}^{++}$influx, resulting in inhibition of transmitter release. The $\mu$-agonists also have a direct postsynaptic effect, causing hyperpolarization and a reduction in neuronal activity. ${ }^{14,15}$ Local anaesthetic, bupivacaine, acts mainly by blockade of voltage-gated
TABLE III Characteristics of motor block

\begin{tabular}{lcc}
\hline & Control & Fentanyl \\
\hline Onset to grade III motor block (min) & $8.8 \pm 3.3$ & $8.6 \pm 4.1$ \\
Duration of grade III motor block (min) & $101 \pm 42$ & $112 \pm 22$ \\
Duration of grade II motor block (min) & $124 \pm 43$ & $139 \pm 30$ \\
Duration of grade I motor block (min) & $151 \pm 46$ & $169 \pm 37$ \\
\hline
\end{tabular}

Values are mean \pm S.D.

No statistically significant differences.

TABLE IV Characteristics of haemodynamic and other parameters

\begin{tabular}{lll}
\hline & Control & Fentanyl \\
\hline Hypotension (MAP $<70 \mathrm{mmHg})$ & $3(14 \%)$ & $9(43 \%)^{*}$ \\
Bradycardia $(\mathrm{HR}<50 \mathrm{bpm})$ & $4(28 \%)$ & $3(14 \%)$ \\
Resp. depression $\left(\mathrm{SaO}_{2}<90 \%\right)$ & 0 & 0 \\
Shivering & $2(9 \%)$ & 0 \\
Itching & 0 & $2(10 \%)$ \\
Nausea & $1(5 \%)$ & 0 \\
Request for pain relief $(n / \%)$ & $13(59 \%)$ & $4(19 \%)^{*}$ \\
\hline
\end{tabular}

Values are numbers (percent).

${ }^{*} P<0.05$, considered significant (Fisher's exact test).

$\mathrm{Na}^{+}$channels in the axonal membrane. ${ }^{16}$ Local anaesthetics may also interfere with synaptic transmission by a presynaptic inhibition of $\mathrm{Ca}^{++}$channels in addition to their effects on nerve conduction. ${ }^{16}$ A combination of these effects may explain the observed synergism between bupivacaine and fentanyl in our study group.

Our method of monitoring sensory and motor blockade was based upon the subjective patient responses. Monitoring of the somatosensory evoked potentials (SSEPs) during spinal block may be a better technique for assessing the degree of sensory and motor blockade; however, results obtained from various studies have not been conclusive. ${ }^{17-19}$ Lund et al. found that isobaric bupivacaine, $18 \mathrm{mg}$ it, despite complete motor block of the lower extremities and sensory blockade up to $T_{8}$ (by pin prick), did not reliably abolish SSEPs from electrical stimulation of the $L_{1}$ and $S_{1}$ dermatome. However, intrathecal bupivacaine had a strong depressant effect on neural afferent transmission and decreased the amplitude of SSEPs. ${ }^{17}$ Therefore, further studies may be necessary to study the duration of bupivacaine-induced spinal block based on subjective patient responses compared to SSEPs.

In this study, $43 \%$ of the patients in the fentanyl-treated group experienced episodes of intraoperative hypotension compared with $14 \%$ in the control group. It has been reported that neuraxial administration of fentanyl with local anaethetics can lead to an increased incidence of hypotension. ${ }^{20}$ Following co-administration of fentanyl 
and local anaesthetic, the increased incidence of hypotension may be related to the higher sensory level achieved, as reported by Adkinsson et al. ${ }^{21}$ However, in our study, the highest sensory levels achieved were $T_{8}$ $\left(T_{5-10}\right)$ and $T_{7}\left(T_{6-8}\right)$ in the control and fentanyl groups, respectively. Therefore, this difference in highest sensory levels may not fully explain the increased incidence of episodes of hypotension. Animal studies have shown that fentanyl does not potentiate the effect of bupivacaine on efferent sympathetic pathways. ${ }^{7}$

Our study also demonstrated that fentanyl, $25 \mu \mathrm{g}(0.3$ $\mu \mathrm{g} \cdot \mathrm{kg}^{-1}$ ) $i t$, reduced the analgesic requirement without increasing the incidence of episodes of desaturation, nausea, or pruritus during the early postoperative period. Belzarena found that fentanyl, $0.5 \mu \mathrm{g} \cdot \mathrm{kg}^{-1}$ and 0.75 $\mu \mathrm{g} \cdot \mathrm{kg}^{-1} \mathrm{it}$, increased the duration of postoperative analgesia in parturients following Caesarean delivery (640 土 $142 \mathrm{~min}$ and $787 \pm 161 \mathrm{~min}$, respectively); however, this increased duration was associated with a decrease in the respiratory rate during the intraoperative period, and an increased incidence of sedation and pruritus related to higher doses of fentanyl. Also, consumption of supplemental analgesics decreased with increasing doses of fentanyl. ${ }^{10}$ In contrast, Hunt $e t$ al. found that increasing the dose of fentanyl $>6.25 \mu \mathrm{g}$ did not increase the duration of analgesia following Caesarean delivery in parturients (192 $\pm 75 \mathrm{~min}$ ); fentanyl, $6.25 \mu \mathrm{g} i$, was the optimal dose for effective perioperative analgesia. ${ }^{2}$ Improved perioperative analgesia following co-administration of fentanyl and bupivacaine can be explained by a synergistic inhibitory action of these two agents on $\mathrm{A} \delta$ and $\mathrm{C}$-fibre conduction.?

In conclusion, fentanyl $25 \mu \mathrm{g}\left(0.3 \mu \mathrm{g} \cdot \mathrm{kg}^{-1}\right)$ it, prolonged the duration of bupivacaine-induced sensory spinal block and reduced the analgesic requirement during the early postoperative period. Our study demonstrates that intrathecal fentanyl acts synergistically to potentiate bupivacaine-induced sensory spinal block.

\section{Acknowledgements}

The authors thank the residents of the Department of Anesthesiology \& Pain Management for their cooperation during this study.

\section{References}

1 Abouleish E, Rawal N, Shaw J, Lorenz T, Rashad MN. Intrathecal morphine $0.2 \mathrm{mg}$ versus epidural bupivacaine $0.125 \%$ or their combination: effects on parturients. Anesthesiology 1991; 74: 711-6.

2 Hunt CO, Naulty JS, Bader AM, et al. Perioperative analgesia with subarachnoid fentanyl-bupivacaine for cesarean delivery. Anesthesiology 1989; 71: 535-40.

3 Akerman B, Arweström E, Post C. Local anesthetics po- tentiate spinal morphine antinociception. Anesth Analg 1988; 67: 943-8.

4 Fraser HM, Chapman V, Dickenson AH. Spinal local anaethetic actions on afferent evoked responses and windup of nociceptive neurons in the rat spinal cond: combination with morphine produces marked potentiation of antinociception. Pain 1992; 49: 33-41.

5 Maves TI, Gebhart GF. Antinociceptive synergy between intrathecal morphine and lidocaine during visceral and somatic nociception in the rat. Anesthesiology 1992; 76: 91-9.

6 Tejwani GA, Rattan AK, McDonald JS. Role of spinal opioid receptors in the antinociceptive interactions between intrathecal morphine and bupivacaine. Anesth Analg 1992; 74: 726-34.

7 Wang C, Chakrabarti MK, Whitwam JG. Specific enhancement by fentanyl of the effects of intrathecal bupivacaine on nociceptive afferent but not on sympathetic efferent pathways in dogs. Anesthesiology 1993; 79: 766-73.

8 Leighton BL, DeSimone CA, Norris MC, Ben-David B. Intrathecal nareotics for labor revisited: the combination of fentanyl and morphine intrathecally provides rapid onset and profound, prolonged analgesia. Anesth Analg 1989; 69: 122-5.

9 Rueben SS, Dunn SM, Dupart KM, O'Sullivan P. An intrathecal fentanyl dose-response study in lower extremity revascularization procedures. Anesthesiology 1994; 81 : 1371-5.

10 Belzarena $S D$. Clinical effects of intrathecally administered fentanyl in patients undergoing cesarean section. Anesth Analg 1992; 74: 653-7.

11 Datta S, Lambert DH, Gregus J, Gissen AJ, Covino BG. Differential sensitivities of mammalian nerve fibers during pregnancy. Anesth Analg 1983; 62: 1070-2.

12 Fagraeus L, Urban BJ, Bromage PR. Spread of epidural analgesia in early pregnancy. Anesthesiology 1983; 58 : 184-7.

13 Bromage PR. A comparison of the hydrochloride and carbon dioxide salts of lidocaine and prilocaine in epidural analgesia. Acta Anaesthesiol Scand 1965; 16: 55-69.

14 Ocana M, Del Pozo E, Barrios M, Robles LI, Bayens $J M$. An ATP-dependent potassium channel blocker antagonizes morphine analgesia. Eur J Pharmacol 1990; 186: 377-8.

15 Dickenson $A H$. Mechanisms of the analgesic actions of opiates and opioids. Br Med Bull 1991; 47: 690-702.

16 Butterworth JF IV, Strichartz GR. Molecular mechanisms of local anesthesia: a review. Anesthesiology 1990; 72 : 711-34.

17 Lund C, Selmar P, Hansen $O B$, Kehlet $H$. Effect of intrathecal bupivacaine on somatosensory evoked potentials following dermatomal stimulation. Anesth Analg 1987; 66: 809-13.

18 Boswell MV, Iacono RP, Guthkelch AN. Sites of action of 
subarachnoid lidocaine and tetracaine: observations with evoked potential monitoring during spinal cord stimulator implantation. Reg Anesth 1992; 17: 37-42.

19 Chabal $C$, Jacobson $L$, Little $J$. Effects of intrathecal fentanyl and lidocaine on somatosensory-evoked potentials, the H-reflex, and clinical responses. Anesth Analg 1988; 67 : 509-13.

20 Gaffud MP, Bansal P, Lawton C, Velasquez N, Watson $W A$. Surgical analgesia for cesarean delivery with epidural bupivacaine and fentanyl. Anesthesiology 1986; 65: 331-4.

21 Adkisson GH, Waters JH, Burger GA. Fentanyl added to lidocaine results in higher spinal anesthetic levels. Anesth Analg 1993; 76: S2. 